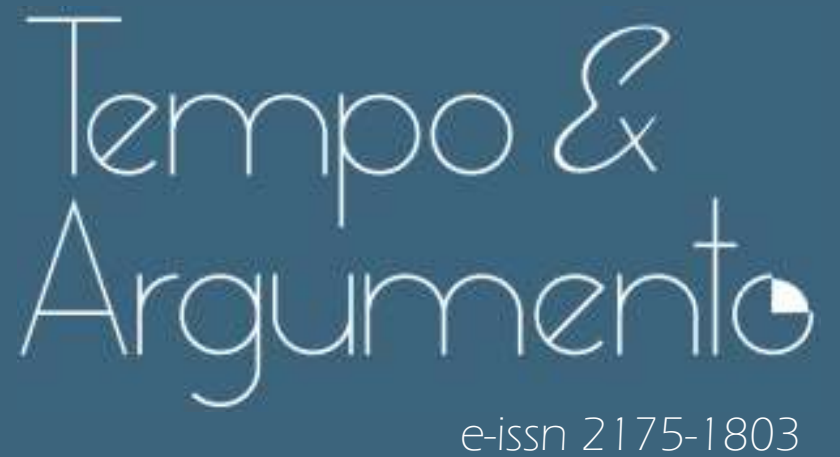

\title{
Representaciones y prácticas docentes en torno a la dictadura de Franco
}

- Néstor Banderas Navarro

Doctorando en Didácticas Específicas (Didáctica de las Ciencias Sociales) por la Universidad de Valencia (UV). Profesor de la Universidad de Valencia (UV).

València - ESPAÑA

uv.es/umveb/universidad/es/ficha-persona

nestor.banderas@uv.es

(1) orcid.org/0000-0001-8807-1919

- Carlos Fuertes Muñoz

Doctor en Historia Contemporánea por la Universidad de Valencia (UV).

Profesor de la Universidad de Valencia (UV).

València - ESPAÑA

uv.es/uwweb/universidad/es/ficha-persona

carlos.fuertes@uv.es

(D) orcid.org/0000-0001-8158-7138

Para citar este articulo (ABNT):

BANDERAS NAVARRO, Néstor; FUERTES MUÑOZ, Carlos. Representaciones y prácticas docentes en torno a la dictadura de Franco. Tempo e Argumento,

Florianópolis, v. 13, n. 33, e0 105, maio/ago. 2021

doi http://dx.doi.org/10.5965/2175180313332021e0105

Recebido: 28/02/2021

Aprovado: 23/05/2021 


\title{
Representaciones y prácticas docentes en torno a la dictadura de Franco $^{1}$
}

\begin{abstract}
Resumen
En este artículo llevamos a cabo un estudio de caso centrado en 5 docentes españoles en relación con el tratamiento educativo que llevan a cabo de la dictadura franquista. Se parte de una contextualización general acerca del periodo histórico de la dictadura de Franco (1936-39 y 1975-78), tema social y políticamente candente que tiene su correlato a nivel educativo al estar presente en el currículo de la educación secundaria y bachillerato. Esta investigación pone el foco en el profesorado, que traduce en el contexto del aula una serie de ideas y representaciones sobre la dictadura, algo que está condicionado por su nivel formativo, el contexto sociopolítico actual y la concreción curricular que se realiza en la normativa educativa. Las representaciones, los saberes y las prácticas que se analizan con estos 5 docentes permiten identificar tendencias, posibilidades y dificultades en la enseñanza de la dictadura de Franco.
\end{abstract}

Palabras clave: Dictadura de Franco; historia; enseñanza de la Historia; profesores.

\section{Representations and teaching practices around the Franco dictatorship}

\begin{abstract}
In this article we carry out a case study focused on 5 Spanish teachers in relation to their educational approach to the Franco dictatorship. It starts from a general contextualization of the historical period in the Franco dictatorship (1936-39 and 1975-78), a socially and politically hot topic that has its correlate at an educational level as it exists in the curriculum of secondary and high school education. This research focuses on teachers, who translate into the classroom context a series of ideas and representations of the dictatorship, which is conditioned by their educational level, the current socio-political context, and the curricular concretion that is carried out in educational regulations. The representations, knowledge, and practices analyzed with these 5 teachers allow us to identify trends, possibilities, and difficulties in teaching the Franco dictatorship.
\end{abstract}

Keywords: Franco dictatorship; History; History teaching; Teachers.

\section{Representações e práticas docentes em torno da ditadura de Franco}

\begin{abstract}
Resumo
Neste artigo realizamos um estudo de caso que enfoca 5 professores espanhóis diante de sua abordagem educacional à ditadura de Franco. Parte-se de uma contextualização geral do período histórico da ditadura de Franco (1936-39 e 1975-78), um tema social e politicamente quente que tem seu correlato em nível educacional, pois existe no currículo do ensino secundário e do ensino médio. Esta pesquisa tem como foco os professores, que traduzem para o contexto da sala de aula uma série de ideias e representações da ditadura, algo condicionado por seu nível educacional, pelo atual contexto sociopolítico e pela concretização curricular realizada nas normas educacionais. As representações, os saberes e as práticas analisadas com esses 5 professores nos permitem identificar tendências, possibilidades e dificuldades no ensino da ditadura de Franco.
\end{abstract}

Palavras-chave: Ditadura de Franco; História; Ensino de História; Professores.

\footnotetext{
Este trabajo fue realizado en el marco del proyecto de investigación "Las representaciones sociales de los contenidos escolares en el desarrollo de las competencias docentes" (PGC2018094491-B-C32), financiado por el Ministerio de Ciencia, Innovación y Universidades del Gobierno de España y cofinanciado por el Fondo Europeo de Desarrollo Regional (FEDER) de la Unión Europea (UE)
} 


\section{La dictadura de Franco como tema sensible en la sociedad, la} política y las aulas españolas del siglo XXI

La dictadura del militar Francisco Franco (1936-39 a 1975-78) surgió en España en el contexto europeo de auge de los fascismos, a partir de un golpe de Estado contra el gobierno democrático de izquierdas elegido en las urnas en 1936, en el contexto de la llamada "Segunda República" (1931 a 1936-39). Esto es, la más profunda -pese a su brevedad- de las experiencias democráticas de la historia contemporánea española dominada hasta entonces -con puntuales excepciones democráticas y autoritarias- por el liberalismo oligárquico y monárquico. El ataque a la democracia y las reformas sociales de los gobiernos republicanos progresistas fue llevado a cabo por militares con importantes apoyos entre la élite empresarial, el mundo católico, los partidos conservadores, la Alemania nazi y la Italia fascista. Pero, a diferencia de lo ocurrido en aquellos países o en Austria, la rápida toma del poder fracasó debido a la notable movilización de las clases populares, los sindicatos y los partidos de izquierdas, dando lugar a la "guerra civil española" (1936-39). El "franquismo", configurado durante una guerra que venció y sacralizó, convirtiéndola en eje de su política de memoria, fue una dictadura personal ultranacionalista, ultracatólica, patriarcal y de clase, con un evidente componente fascista articulado a través del partido único, Falange (SAZ, 2004).

Una dictadura que desplegó una política represiva multimodal que afectó a una gran cantidad de facetas de la vida de los ciudadanos y que, con una particular intensidad en sus primeros años - marcados por los encarcelamientos y fusilamientos masivos-, provocó el exilio de cientos de miles de "vencidos" y le garantizó su consolidación y supervivencia durante 40 años (BABIANO; GÓMEZ; MíGUEZ; TÉBAR, 2017). Así, existe un consenso historiográfico unánime respecto a la centralidad de la represión/violencia institucional como componente estructural del franquismo, que persistió mucho más allá del final de la guerra e, incluso, más allá de la muerte del dictador (VIÑAS, 2015), refiriéndose al período como una "paz incivil" (CASANOVA, 2002, p. 5).

Pese al miedo y la paralización social derivadas, la creciente movilización ciudadana a favor de las libertades y la igualdad fue ganando intensidad en los 
años 1960 y más aun tras la muerte de Franco, en 1975, impidiendo la continuidad de la dictadura e impulsando un proceso de democratización: la llamada “Transición” (1975-82). Proceso que, sin embargo, se saldó a través de la llamada "Ley de Amnistía" (1977), que permitió la salida de la cárcel de los antifranquistas y la vuelta a España de los exiliados, con la paralela impunidad absoluta de los cuadros de la dictadura artífices de la represión, sin la depuración de instituciones estatales clave, como el ejército o la judicatura, y sin que se articulara una memoria democrática y antifranquista transversal. Se difundió entonces, en las distintas fuerzas políticas y los sectores sociales, un cierto "pacto de silencio y olvido", entendido como forma de consolidar la democracia y evitar nuevos conflictos, en una sociedad traumatizada por la violenta experiencia de guerra y dictadura (AGUILAR, 2006; FUERTES, 2017; SAZ, 2007).

Más de 40 años después de su desaparición y de la difusión de dicho "pacto de silencio", la dictadura franquista juega hoy un rol central en el debate público de la España democrática, generando importantes controversias y contribuyendo notablemente a la construcción de imaginarios y proyectos políticos en disputa. Así, en las identidades y las organizaciones de izquierdas tiene un peso destacado el "antifranquismo" -en cierta medida como variante española del antifascismo internacional-, habiéndose articulado desde finales de los años 1990 un potente movimiento social de "recuperación de la memoria histórica” que situó en el centro del debate político la necesidad de realizar exhumaciones en las incontables fosas comunes en las que la dictadura escondió más de 100.000 fusilados $^{2}$. Como resultado de dichas movilizaciones, los gobiernos progresistas del siglo XXI, tanto en el ámbito estatal (2004-11 y 2018) como en el regional y local, han impulsado diversas políticas de "memoria democrática", entendida esta como un elemento central en la salud de las democracias (BALDÓ, 2017).

Sin embargo, dichas políticas siguen adoleciendo de notables carencias señaladas por organismos internacionales (DE GREIFF, 2014) y manteniendo la

\footnotetext{
2 Se calcula que el número de víctimas mortales por fusilamientos llevadas a cabo por los sublevados entre 1936 y 1945, durante la guerra y los primeros años de la dictadura, se sitúa en una cifra superior a 150.000, siendo estos datos provisionales a partir de la investigación regional llevada a cabo por distintos historiadores (BABIANO; GÓMEZ; MíGUEZ; TEBAR, 2017).
} 
impunidad de unos crímenes del franquismo cuyas víctimas intentan judicializar fuera de España a través de la llamada "Querella Argentina" (MONTOTO, 2020). Dichos límites políticos y judiciales conectan con la inhibición y rechazo de las políticas de memoria democrática de una derecha con un discurso equidistante y ambivalente. Este mismo discurso remite a la pervivencia de una preocupante banalización de la dictadura entre heterogéneos sectores sociales que prefieren mantener vivo el "pacto de silencio" y no "remover el pasado". Más recientemente, este fenómeno ha dado un giro aún más peligroso con el auge de la extrema derecha, que vuelve a entrar en el parlamento por primera vez desde 1982 a través de Vox -y con fuerza: tercer partido con más del 15\% del voto en las elecciones generales de 2019-, amplificando enormemente su discurso beligerante contra las políticas de memoria y de normalización e, incluso, de reivindicación del franquismo (BERNECKER; BRINKMANN, 2009; CASALS, 2020).

Todo este contexto tiene su traslación en el ámbito educativo, donde la historia de la dictadura franquista debería abordarse según la legislación en 3 cursos que suponen finalización de etapa: 6o de Educación Primaria (11-12 años), 4o de Educación Secundaria Obligatoria -ESO- (15-16 años) y 2o de Bachillerato (17-18 años). Así, este pasado reciente asociado a traumas colectivos, como la represión o el exilio masivos, clave para entender la España actual, se convierte en uno de los temas sensibles por excelencia en las aulas. Un tema sensible se puede definir como un tema controvertido a nivel social y con notable presencia mediática, lo cual implica toda una serie de particularidades en su tratamiento educativo (FALAIZE, 2010). Estos temas se han analizado también desde el paradigma de los conflictos sociales candentes (LÓPEZ FACAL; SANTIDRIÁN, 2011), questions socialment vives (LEGARDEZ; SIMMONNEAUX, 2006) o controversial issues (EVANS; NEWMANN; SAXE, 1996), coincidiendo en que, pese a sus dificultades, deben estar presentes en el aula de Historia. Ciertamente, tienen notables potencialidades para la adquisición de las competencias de pensamiento histórico, la construcción de una ciudadanía crítica y el reforzamiento de la cultura democrática entre unos estudiantes habitualmente más interesados hacia este tipo de temas (CARRETERO; BORRELLI, 2008; CUESTA, 2011; KRIGER, 2011). 
Partiendo de estas premisas, y aunque el contraste es enorme con las muy avanzadas y consolidadas investigaciones históricas sobre la dictadura, en la última década se ha producido un cierto avance de las investigaciones educativas sobre su enseñanza, paralelo tanto a la expansión del área académica de Didáctica de las Ciencias Sociales en las universidades españolas como al avance de los debates públicos sobre la memoria del período. Estas investigaciones se han concentrado en los manuales escolares o libros de texto -recurso hegemónico en las aulas españolas-, destacando el predominio de un enfoque aséptico focalizado en la evolución político-económica y lamentándose una insuficiente actualización respecto a la historiografía académica en aspectos clave, con la consiguiente reproducción y/o no impugnación de determinadas narrativas legitimadoras del franquismo de gran arraigo social (FUERTES, 2018a; VALLS, 2009).

Así, se ha rastreado la perpetuación en los manuales de la narrativa equidistante impulsada por el franquismo sobre las causas y la naturaleza de la Guerra Civil, que tiene la virtud de exculpar a los golpistas haciendo un reparto simétrico de responsabilidades o presentando la guerra como un fenómeno inevitable (FUERTES, 2018b). Se ha constatado, igualmente, una visión superficial e insuficientemente crítica de la represión franquista, no subrayándose siempre su centralidad, concentrándose en la represión inicial y haciéndolo con una visión cuantitativa de los encarcelamientos y fusilamientos que deja fuera aspectos clave de la dictadura: la dura vida cotidiana en los campos de concentración; los trabajos forzados; o, entre otros muchos, la represión económica, cultural y de género (FUERTES; IBÁÑEZ, 2019). O, entre otras cuestiones, se ha cuestionado la escasa atención en los libros de texto a las políticas de memoria y los debates actuales al respecto, sin apenas referencias a los objetivos, logros y límites de los movimientos de recuperación de la memoria de las víctimas del franquismo (DÍEZ, 2020). Mucho más precario, sin embargo, es nuestro conocimiento sobre otros objetos y sujetos escolares fundamentales, más allá de lo que plantean los libros de texto, a fin de comprender su traducción/recepción, las dinámicas generadas en las aulas y los procesos cotidianos de construcción de significados en torno a un tema tan sensible en la sociedad, la política y la educación española. 


\section{El profesorado como sujeto de estudio}

Precisamente con la intención de enriquecer nuestro conocimiento, nuestro trabajo pone el foco en el profesorado como sujeto de estudio desde la premisa de que sus representaciones, saberes y prácticas son claves para (re)interpretar el currículo y su traducción en los libros de texto y, por tanto, para configurar el imaginario histórico del alumnado (BELTRÁN, 2006; CHERVEL, 1991; CLARK; YINGER, 1979; GONZÁLEZ, 2018; MARTÍNEZ; SOUTO; MONTEIRO, 2007). Al efecto, nos inspiramos en las escasas investigaciones sobre las representaciones, decisiones y acciones cotidianas de los docentes en la enseñanza del pasado reciente español (DELGADO, 2014; MARTÍNEZ, 2013), así como en las de otros países que padecieron en el siglo XX dictaduras de extrema derecha similares a la española (ACEITUNO, 2012; GONZÁLEZ, 2014).

Entendida como primera aproximación de una investigación monográfica más amplia en el marco de una tesis doctoral en curso centrada en la enseñanza de la dictadura franquista en la Comunidad Valenciana -4ạ región de España en términos demográficos-, en este trabajo adoptaremos un enfoque eminentemente cualitativo, analizando de forma matizada y detallada las representaciones y prácticas de 5 docentes españoles de Educación Secundaria Obligatoria y Bachillerato en torno a la enseñanza de la dictadura franquista. Así, nuestro objetivo es comprender en profundidad una serie de casos docentes no para deducir o concluir una representatividad respecto a los casos posibles, sino para bucear en su particularidad, unicidad y complejidad, así como para detectar tendencias y variables sobre las que deberemos profundizar en sucesivos trabajos (REDON; ANGULO, 2017).

En este sentido, la selección de los docentes analizados se ha realizado de modo no probabilístico, casual o por facilidad de acceso, así como empleando la técnica de bola de nieve (BISQUERRA, 2014; FLICK, 2007). Pese a ello, tal y como puede apreciarse en la tabla 1, hemos tratado de garantizar en los participantes un cierto equilibrio y correspondencia con el contexto educativo español en variables como el sexo, la formación disciplinar, la formación pedagógica, la experiencia laboral o el tipo de centro (GUIMERÁ, 1991; MERCHÁN, 2005). Debe destacarse que en España el cuerpo de docentes de Historia en ESO y 
Bachillerato se encarga también de la materia de Geografía. Por ello, aunque 4 de los entrevistados tienen una formación disciplinar especializada en Historia, 2 de ellos recibieron también formación en Geografía; mientras que la quinta entrevistada es graduada en Geografía, sin formación inicial sólida en Historia, un perfil escaso pero existente. Conviene aclarar, asimismo, que la formación pedagógica del profesorado español se realiza con posterioridad a la formación disciplinar de grado, caracterizándose hasta 2010 por un superficial curso intensivo de 3 meses de duración -el llamado CAP (Certificado de Aptitud Pedagógica), obtenido por 4 de los participantes- y solo a partir de entonces por un mucho más ambicioso y completo Máster en Profesor/a de Educación Secundaria.

Tabla 1 - Datos básicos los docentes analizados

\begin{tabular}{|c|c|c|c|c|}
\hline PROFESOR & $\begin{array}{l}\text { FORMACIÓN } \\
\text { DISCIPLINAR }\end{array}$ & $\begin{array}{l}\text { FORMACIÓN } \\
\text { PEDAGÓGICA }\end{array}$ & $\begin{array}{c}\text { EXPERIENCIA } \\
\text { LABORAL }\end{array}$ & CENTRO \\
\hline $\begin{array}{l}\text { Profesora } 1 \\
\text { (P1) }\end{array}$ & $\begin{array}{l}\text { Geografía e } \\
\text { Historia (espec. } \\
\text { Historia e } \\
\text { Historia del } \\
\text { Arte) }\end{array}$ & $\begin{array}{l}\text { Certificado de } \\
\text { Aptitud } \\
\text { Pedagógica }\end{array}$ & 35 años & Público \\
\hline $\begin{array}{l}\text { Profesor } 2 \\
\text { (P2) }\end{array}$ & Historia & $\begin{array}{l}\text { Certificado de } \\
\text { Aptitud } \\
\text { Pedagógica }\end{array}$ & 5 años & Público \\
\hline $\begin{array}{l}\text { Profesor } 3 \\
\text { (P3) }\end{array}$ & $\begin{array}{l}\text { Geografía e } \\
\text { Historia (espec. } \\
\text { Historia) }\end{array}$ & $\begin{array}{l}\text { Certificado de } \\
\text { Aptitud } \\
\text { Pedagógica }\end{array}$ & 33 años & Público \\
\hline $\begin{array}{l}\text { Profesor } 4 \\
\text { (P4) }\end{array}$ & Historia & $\begin{array}{l}\text { Certificado de } \\
\text { Aptitud } \\
\text { Pedagógica }\end{array}$ & 13 años & Público \\
\hline $\begin{array}{l}\text { Profesora } \\
5 \text { (P5) }\end{array}$ & Geografía & $\begin{array}{l}\text { Máster en } \\
\text { Profesor/a de } \\
\text { Secundaria }\end{array}$ & 3 años & $\begin{array}{l}\text { Privado } \\
\text { católico } \\
\text { (concertado) }\end{array}$ \\
\hline
\end{tabular}

Fuente: Elaborada por los autores, 2021.

A fin de aproximarnos en profundidad a los 5 docentes seleccionados, hemos optado por la construcción de historias de vida profesionales que nos permitan comprender sus representaciones y decisiones docentes en torno a la dictadura franquista insertándolas en el marco más amplio de su formación, experiencia y concepciones sobre la profesión docente y la enseñanza de la historia (GOODSON, 2004; HERNÁNDEZ; SANCHO, 2007). Más concretamente, hemos llevado a cabo -entre octubre y diciembre de 2020- entrevistas semi- 
estructuradas, combinando la indagación sobre unos objetivos básicos previamente definidos con la flexibilidad para realizar modificaciones durante el diálogo, tratando en todo momento de construir una conversación profesional, pero al tiempo relajada y motivadora (RUIZ OLABUÉNAGA, 2009). A fin de guiar la entrevista, diseñamos un cuestionario con preguntas abiertas combinadas en momentos puntuales con la discusión a partir de recursos didácticos o susceptibles de ser utilizados en el aula, tales como una página de un libro de texto, fotografías de la época franquista, un fragmento de una popular serie televisiva de ficción histórica ambientada en los últimos años del franquismo o una noticia actual que muestra los debates abiertos en torno a la "memoria" de la dictadura.

La narración que constituye cada una de las entrevistas ha sido analizada de manera profunda, codificando su contenido (STRAUSS; CORBIN, 2002) y agrupándolo en categorías analíticas que permiten facilitar posteriormente su análisis. En dicha fase ha sido de gran utilidad la recopilación y el análisis de materiales elaborados y/o utilizados por los docentes entrevistados (tales como Unidades Didácticas de confección propia en formato papel o web, vídeos o dossiers de fuentes), los cuales permiten ubicar sus relatos en un contexto más amplio y comprender así con mayor detalle determinadas declaraciones verbales y cómo estas se plasman de forma más o menos coherente en sus clases, espacio clave para la comprensión de las prácticas, al que sin embargo no podremos acceder al no haber realizado observaciones de aula. En las siguientes páginas nos detendremos en diversas dimensiones, poniéndolas en relación con las investigaciones precedentes sobre los docentes españoles y otros países con casos similares. Para empezar, trazaremos una visión panorámica sobre diversos factores y contextos clave para comprender la enseñanza del franquismo en la España actual que pueden rastrearse en las distintas entrevistas. A continuación, profundizaremos en los distintos posicionamientos ante la enseñanza del franquismo que pueden detectarse en los 5 docentes, poniendo el foco en los sentidos y contenidos priorizados. Al efecto, trataremos de diferenciar sus representaciones y prácticas analizando similitudes y divergencias entre ellos y poniéndolos en relación con teorías basadas en modelos ideales sobre las 
actitudes docentes ante temas controvertidos (KELLY, 1986; LÓPEZ FACAL; SANTIDRIÁN, 2011), siendo en cualquier caso plenamente conscientes de la imposibilidad de encajar en clasificaciones rígidas las complejas y fluidas prácticas docentes (PÉREZ GÓMEZ, 1995).

\section{Factores y contextos en la enseñanza del franquismo}

Cuando se les pregunta, al inicio de la entrevista, si existen contenidos conflictivos en las clases de Historia, los 5 profesores identifican de forma espontánea la dictadura franquista, manifestando al tiempo una cierta inseguridad en cuanto a la mejor forma de abordar este tipo de temas sensibles. Algo que puede asociarse a ciertos factores que operan en gran medida como dificultades $y$, en cualquier caso, como condicionantes de las decisiones docentes (TUTIAUX-GUILLON, 2006). Un primer factor que entendemos explicaría dicha inseguridad remite a las carencias formativas. Por un lado, a la falta de formación disciplinar específica sobre la historia del franquismo, dada su reciente -y aún escasa- inclusión en los planes de estudio universitarios de Historia y su ausencia en los de otras titulaciones, problema constatado por investigaciones previas (MARTíNEZ, 2013). Así, los 2 profesores más mayores (P1 y P3) y la graduada en Geografía (P5) no recibieron ningún tipo de formación inicial al respecto. Frente a ello, debe destacarse que, lejos de la resignación, se aprecia entre varios de los entrevistados (P1, P2 y P3) una conciencia de este problema y un esfuerzo de autoformación sobre la historia reciente de España a través de la lectura de bibliografía especializada y la asistencia a cursos de formación permanente. Por otro lado, la mencionada inseguridad se ve reforzada, a nuestro juicio, por la paralela falta de formación en didáctica de la Historia y más concretamente sobre el abordaje de temas conflictivos detectable en todos los entrevistados, aunque esta dimensión apenas es verbalizada, demostrando una escasa toma de conciencia respecto a la misma.

Un segundo factor destacable remite al contexto sociopolítico actual, el cual parece operar en 2 sentidos contrapuestos y aparentemente contradictorios, que dan cuenta de la complejidad del asunto. Por un lado, el auge de los movimientos y las políticas de memoria democrática desde la 
primera década del siglo XXI, con su claro impacto en la esfera pública, parece haber favorecido una evolución hacia una mayor atención a la enseñanza del franquismo, coincidiendo con lo señalado por otros trabajos (DÍEZ, 2020; LAMIKIZ, 2011). Así lo reconoce el docente P3 -con 33 años de experiencia-, mientras puede leerse entre líneas en los relatos de los otros entrevistados.

Sin embargo, por otro lado, la paralela falta de consenso sociopolítico respecto al pasado franquista y de una sólida memoria democrática, agudizado con el reciente auge de la extrema derecha en España, parece reforzar la inseguridad docente a la hora de abordar el franquismo. No en vano, dicho crecimiento de la ultraderecha se está traduciendo ya, en la línea de fenómenos como "Escola Sem Partido" en Brasil (PENNA, 2018), en crecientes denuncias judiciales -y mediáticas- que señalan, de forma insistente, a los historiadores y docentes identificados como "progresistas" o contrarios al conservadurismo español(ista) en planos como las identidades nacionales, la igualdad de género o la memoria democrática (RODRÍGUEZ, 2021). En este sentido, entendemos que ello podría estar favoreciendo un cierto temor latente ante las posibles acusaciones de "adoctrinamiento" entre parte de las familias y el alumnado por asumir un posicionamiento docente crítico con la dictadura desde el conocimiento histórico riguroso, una realidad que ha sido constatada en otros países con pasados similares (GONZÁLEZ, 2014).

Desde luego, los 5 profesores coinciden en señalar espontáneamente un crecimiento reciente entre el alumnado adolescente de las posturas contrarias a la memoria democrática y de banalización -cuando no identificación- con el franquismo. Algo que el Profesor 3 considera con una particular preocupación lo que contrasta con miradas más acríticas (P4 y P5)- por ser un reflejo del mencionado crecimiento de la extrema derecha:

Y ahora, no es que sea prudente [...] pero soy más consciente de que el huevo de la serpiente está ahí en las clases, lo noto, lo noto, minoritario aún... [...] sí que veo un poquito un revivir del franquismo sociológico, el fenómeno VOX sí que se nota en las aulas [...] Gente que se mira cuando tú dices algo... de las dictaduras, Hitler, Mussolini, Franco y tal, siempre hay alguien que mira a otro a ver qué cara pone el otro y tal [...]. (P3, 2020. Información verbal.) 
Este hecho se puede observar en gestos como esos o en complementos de vestimenta, dibujos, comentarios, lemas o cánticos propios del franquismo, el fascismo y el ultranacionalismo español conservador que, entendemos, pueden contribuir a generar una "atmósfera de transmisión" (GONZÁLEZ, 2014, p. 122) menos propicia para un tratamiento crítico de la dictadura. La rápida censura o problematización de estas actitudes por todos los docentes entrevistados nos muestra, en cualquier caso, que pese a las tensiones que puedan generar sí se asume un posicionamiento reactivo o de "beligerancia positiva y explícita" asociado a la concepción de la escuela como un espacio democrático con una serie de valores compartidos (Trilla, 1992).

Sí, y algún gesto, como que simpatizan o intentan imitar, o algún saludo [imita el saludo fascista] [...] Es verdad que en algunas ocasiones como estas sí que acudo a corregir comportamientos o, por lo menos, que ellos vean qué es realmente lo que estás dibujando, o lo que estás haciendo, qué significado tiene, o para qué se utilizó, un poco para romper con esa ideología que ellos se piensan que es gracioso imitar un símbolo que realmente creo que no conocen el significado que tiene. Lo han visto, pero no lo reconocen, toda la carga significativa que puede llevar detrás. (P5, 2020. Información verbal.)

Un tercer factor que emerge como condicionante para el tratamiento del franquismo es el contexto o marco legal educativo. Así, el currículo es considerado excesivo e inabarcable, coincidiendo con lo apuntado por investigaciones precedentes que señalan la tendencia del profesorado a percibirlo como el principal factor limitador del tratamiento problematizado y detallado de los pasados conflictivos recientes (ACEITUNO, 2012; MARTÍNEZ, MUÑOZ; SÁNCHEZ-AGUSTÍ, 2019; WATERSON, 2009). En el caso de 20 de Bachillerato, último curso previo a la universidad, el programa oficial abarca, siguiendo la tradición nacionalista y enciclopedista de las "historias generales" decimonónicas, la Historia de España desde la Prehistoria hasta la actualidad, perpetuando la escasa atención escolar a la historia reciente (MAESTRO, 2002). Sin embargo, en la Comunidad Valenciana -región objeto de nuestro estudio-, la acotación a los siglos XIX-XX de los contenidos objeto de las pruebas externas finales de Evaluación para el Acceso a la Universidad (EVAU), favorece, de facto, 
un currículum "real" más limitado y promueve -o no dificulta tanto- el tratamiento del franquismo al incrementar las posibilidades de que el alumnado pueda ser examinado sobre el mismo (MAINER, 2020).

Pese a ello, se aprecia en este curso una menor inversión de tiempo y un tratamiento menos pormenorizado que el realizado para las etapas anteriores, situadas al principio del curso. Atisbamos aquí el arraigo de una problemática lógica disciplinar que prioriza la profundización en la historia no reciente, argumentando que el conocimiento detallado de dicho pasado es condición necesaria para la comprensión de una historia reciente/actual a la que, como consecuencia, no se llega o se llega, a final de un curso particularmente estresante, con agotamiento y de forma muy superficial (VALLS, 2009). Asimismo, incluso en aquellos docentes que, demostrando la importancia de su voluntad y agencia respecto al currículo, se esfuerzan por ajustar temporalmente los contenidos a fin de trabajar el franquismo y la transición a la democracia, se detectan problemas para abordar en detalle estos períodos:

No, a ver... ni en $2^{\circ}$ de Bachillerato con voluntad se puede trabajar profundamente. Es una locura, es una locura. Yo la primera vez que he llegado a 1982 fuera de tiempo, en una semana, fue hace 2 años. Pero una cosa es [que] cuando tienes un objetivo fuerzas para llegar ahí. (P3, 2020. Información verbal.)

En 4을 de ESO, último curso de la enseñanza obligatoria y, por tanto, aquel al que asiste un mayor número de alumnado, el currículo emerge también como un obstáculo que dificulta el tratamiento del tema, constatándose en los docentes entrevistados una mayor superficialidad respecto a 2 o de Bachillerato. El programa oficial establece para este curso unos vastos contenidos que abarcan desde el final del Antiguo Régimen hasta el mundo actual, integrando contenidos de la historia universal, europea y española, así como de la historia del arte. Así, es frecuente la crítica al exceso de contenidos que, se entiende, favorece un tratamiento enormemente simplificado: "[...] el temario de 4을 ESO me parece todo un despropósito porque no puedes meter ahí todo mezclado, toda la historia, es... es lo más... el esquema del esquema”. (P3, 2020. Información verbal.) 
Este malestar con el currículo se traduce en algunos casos en una activa (re)interpretación docente para dar un mayor peso al tratamiento del franquismo, demostrando que los condicionantes -en este caso, el marco legal- no son barreras insalvables.

En cualquier caso, ante este factor como ante otros, se aprecian en los 5 casos estudiados distintas representaciones y prácticas que remiten a los posicionamientos y decisiones individuales de cada uno de los docentes entrevistados. En efecto, un análisis individualizado de los distintos posicionamientos de los cinco docentes nos permite detectar diferencias destacables en función de la traducción y concreción de los factores y contextos mencionados que cada uno realiza. Algo que debe ponerse en relación a su vez con los sentidos que otorgan al aprendizaje de este pasado conflictivo, pero, también, con sus representaciones más amplias acerca de la naturaleza y las finalidades de la historia escolar. Al respecto, una primera conclusión es que, aunque todos asumen un ejercicio de la profesión tendente a formar ciudadanos críticos y a educar en los Derechos Humanos, en línea con otras investigaciones (GONZÁLEZ, 2018), el análisis del abordaje del franquismo muestra importantes matices individuales en la concepción de la disciplina y en la asunción de posicionamientos coherentes con dichas declaraciones generales descontextualizadas.

No obstante, a tenor de los ejemplos mencionados y materiales facilitados, todos dedican un espacio al franquismo en sus clases, alejándose de aquellos docentes que lo eluden completamente (HERNÁNDEZ, 2014; VALLS, 2009). Aun así, apreciamos notables diferencias en el grado de profundidad o superficialidad con que dicen hacerlo y en su mayor o menor impugnación de las narrativas legitimadoras del franquismo desde el conocimiento histórico riguroso. Pasemos, pues, al análisis de dichas diferencias.

\section{Un tratamiento comprometido del franquismo}

Para empezar, detectamos que los profesores 2 y 3 son quienes realizan una apuesta más decidida por incluir el tratamiento del franquismo en sus propuestas didácticas, abordándolo con considerable detalle tanto en 4ํ de ESO 
como en 2 o de Bachillerato. Dicho detalle no implica la exclusiva centralidad en los contenidos político-institucionales y económicos dominantes en los manuales, tales como la ideología del franquismo, las pugnas políticas entre diferentes familias, la oposición clandestina, el contexto internacional o el cambio de la política económica autárquica a la liberalización. Así, sin ser ignorados, se aprecia una diversificación y ampliación de estos contenidos. A través de la lectura de bibliografía académica y otras vías formativas, estos docentes superan la narrativa nacional-estatal y androcéntrica hegemónica en los manuales (FUERTES, 2019; IBÁÑEZ, 2016) incluyendo una mayor atención a la historia local y a la historia de las mujeres bajo la dictadura. Igualmente, ambos son los que con mayor coherencia, profundidad y sistematicidad abordan la represión franquista, la cual consideran como una cuestión central al interrogarles sobre aquellos temas que el alumnado debería aprender prioritariamente sobre la dictadura. La renovación de los contenidos va acompañada, además, en ambos casos, por una renovación de los métodos y las fuentes utilizados en su enseñanza.

Junto a estas características comunes se aprecian, en cualquier caso, ciertas diferencias y matices interesantes. El Profesor 3, con más de 30 años de experiencia, es aquel que manifiesta un mayor interés por el tratamiento de la represión -"me apasiona, he leído mucho, he trabajado y mucho y tal..." (P3, 2020. Información verbal.)-, que está en plena consonancia con sus propuestas didácticas en el aula. Las suyas son aquellas que de forma más sistemática impugnan las narrativas legitimadoras del franquismo y contribuyen a visibilizar su carácter profundamente represivo. Así, en sus materiales se observa cómo incluye propuestas de trabajos monográficos, tanto para 4으 ESO como para 2ㅇ de Bachillerato en que aborda los campos de concentración, la geografía represiva local -a través de salidas de campo-, la específica represión contra homosexuales, mujeres o maestros o el análisis de la misma a partir del arte, la literatura, el teatro o el cine.

En su relato se aprecia, asimismo, una progresiva mayor atención e “intensidad" en el tratamiento de la historia reciente de España paralelas a su emergencia como tema candente a nivel social (LAMIKIZ, 2011). Un proceso que 
habría favorecido una cierta revisión personal de una inicial visión más complaciente de la transición y una identificación con las demandas de memoria democrática, en un ejemplo claro de la incidencia del cambiante contexto sociopolítico en las prácticas docentes:

[...] El tema de la Guerra Civil, la memoria histórica y democrática y todo eso, que yo reconozco que lo he ido intensificado en los años, siempre lo he explicado, pero al principio intentaba no ponerme tanto... darle tanta intensidad. Lo tocaba, pero no profundizaba, no hacía trabajos específicos. Después empecé a hacer trabajos de historia oral y últimamente se ha convirtiendo en algo súper intenso, 15, 20 años. Y los últimos 2 o 3 años muy intenso. (P3, 2020. Información verbal.)

En cuanto a su concepción general de la disciplina y sus finalidades, argumenta él que ofrece y enseña una "historia para ciudadanos" y "adoctrina en la carta de la declaración de Derechos Humanos" (P3, 2020. Información verbal.). Este docente identifica una serie de temas sensibles que aparecen en las aulas y que facilitan particularmente la concreción de estas finalidades: la cuestión territorial de España, las desigualdades de género, las migraciones, la pena de muerte y, ciertamente, la historia reciente de España. Sus comentarios y la consulta de diferente material pedagógico facilitado por el docente permiten observar que lleva a cabo un tratamiento explícito de estos problemas en perspectiva histórica, algo que se ve favorecido por su dilatada experiencia profesional, que considera un activo: "ahora [...] tal vez soy más imprudente porque estoy más seguro de mí mismo” (P3, 2020. Información verbal.). Siguiendo la clasificación de los posibles posicionamientos docentes ideales o teóricos ante temas controvertidos de Kelly (1986) y López Facal y Santidrián (2011), podríamos ubicar al Profesor 3 como cercano a la llamada "imparcialidad comprometida", la más deseable según estos autores. Una actitud que implica un abordaje decidido salvando los impedimentos del currículo, visibilizando las distintas opiniones del alumnado, pero expresando también la propia postura, siempre desde el compromiso con los consensos historiográficos y los derechos humanos.

Aunque próximo en muchos aspectos al anterior, el Profesor 2 resulta más difícil de clasificar respecto a estos parámetros, ilustrando los límites y los 
problemas de este tipo de propuestas taxonómicas. Este docente parte de una mirada crítica que él considera "reparadora", dado que coincide en señalar la necesidad de educar definiendo la dictadura franquista desde su naturaleza de régimen político criminal y de combatir las lecturas benévolas que han surgido recientemente en España. Así, en una unidad didáctica propia elaborada como alternativa o complemento a las insuficiencias detectadas en los manuales, aborda con detalle determinados aspectos particularmente controvertidos de la historia de la dictadura, como la represión y sus particularidades de género: las violaciones, el rapado de pelo o el robo de hijos a madres presas. Sin embargo, no muestra la misma sistematicidad y diversificación en el análisis de las modalidades de la represión que el profesor anterior ni aborda con el mismo detalle otras cuestiones clave como el periodo de transición a la democracia. Consideramos que las diferentes actividades, propuestas y actualizaciones del currículo de este docente, situado al inicio de su carrera, son un ejemplo de un profesional que se sitúa en un proceso de búsqueda, de configuración de un perfil docente propio y de asunción de una serie de ideas con las que materializar su enseñanza.

Un análisis detallado de su relato y de los materiales facilitados permiten situarlo a medio camino entre la "imparcialidad neutral" y la "imparcialidad comprometida" (KELLY, 1986; LÓPEZ FACAL; SANTIDRIÁN, 2011), dado que sus puntos de vista no siempre se manifiestan, bajo el paraguas de una pretendida neutralidad que, sin embargo, tiene mucho de apariencia y mecanismo de protección consciente:

El docente nunca [...] debe dar opiniones personales, más que nada porque [...] excepto en casos en que todo el mundo pienso que estaríamos de acuerdo, ¿no? Como por ejemplo, el Holocausto judío [...] o la defensa de los valores de la democracia y demás. Pero, al final, el posicionamiento debe intentar ser neutral en el sentido de no verter opiniones personales porque, al final, un docente no está en igualdad de condiciones con sus alumnos. El docente, al final, si dice una opinión, eso va a misa, es una sentencia. [...] Posicionarte en contra de la monarquía, pues para mí sería una opinión que no es apropiada en clase [...] debes dar los instrumentos [...] y que ellos mismos sean capaces de tener una opinión crítica respecto a esa institución [...] al final nosotros como personas no nos podemos desprender de nosotros, y nuestro marco metodológico y teórico del cual 
tampoco nos podemos desprender... (P2, 2020. Información verbal.)

Como vemos, ubicándose en una posición ambigua, el Profesor 2 trata de evitar cualquier opinión personal, que no considera formativa, y sitúa el conocimiento historiográfico como una suerte de refugio ante el que protegerse como profesional a la hora de abordar cualquier debate sobre cuestiones controvertidas. Este docente reconoce, no obstante, que es imposible desprenderse a nivel individual de un sistema de creencias políticas o de paradigmas científicos en la concreción escolar de un tema u otro. Asimismo, asume su postura crítica ante ciertos temas y reconoce, implícitamente, construir discursos con apariencia neutral que sí tienen un objetivo político. Se evidencia, así, la complejidad que supone tratar de asumir un rol imparcial y comprometido al mismo tiempo, constatando la influencia de la ideología en la configuración profesional del docente.

\section{Tensiones para la concreción de un enfoque crítico}

En cuanto a la Profesora 1, el suyo es un caso particularmente complejo que, compartiendo algunos aspectos con los profesores 2 y 3 respecto a su visión sobre el franquismo y las políticas de memoria, nos permite apreciar diversas tensiones en la concreción de un enfoque crítico en el abordaje de estos contenidos. Esta docente, con más de 30 años de experiencia, está inspirada por los paradigmas historiográficos marxistas predominantes en su etapa de formación en las universidades españolas (GUIMERÁ, 1991). Así, asume una visión esencialmente crítica o contranarrativa (RÜSEN, 2004) de la historia escolar, entendiendo que:

es la herramienta fundamental para entender el presente y para forjarte como sujeto político" e intentando en sus clases "desenmarañar toda la información que hay en un libro para ir a lo básico: quién tiene el poder económico, quién tiene el poder político, sin eso no se entiende nada. (P1, 2020. Información verbal.)

Entiende que el conocimiento histórico es esencialmente conflictivo y así parece visibilizar esta idea en el aula, enfocando sus explicaciones de un modo complejo desde la premisa de que "un buen profesor tiene que cuestionar las 
visiones históricas que se dan" (P1, 2020. Información verbal.) e incluyendo, por ejemplo, el tratamiento en perspectiva histórica de problemas del presente no explicitados en el currículum como la corrupción política en la historia contemporánea de España (PRESTON, 2019).

En cuanto al tema que nos ocupa, ciertamente comparte con los 2 profesores anteriores su preocupación ante la extensión de una mirada complaciente, amable y benévola hacia el franquismo por la eclosión de posturas de extrema derecha en la política española que banalizan la dictadura y atentan contra cualquier política memorialista. Esta docente nacida a principios de los 1960 articula una narrativa muy crítica con la dictadura y con la falta de políticas de justicia y memoria democrática: "el haber hecho una transición que fue una rendición [...] no hay un punto y aparte, no hay una revisión de la dictadura, y entonces esto pues crea déficits democráticos importantes" (P1, 2020. Información verbal.). Su enfoque, que podríamos considerar militante, la conduce a tener unas ideas muy claras en torno a lo que pretende transmitir al respecto al alumnado. Sin embargo, apreciamos que la notable implicación personal de esta profesora en relación con sus percepciones políticas y la lectura realizada de la experiencia familiar durante la dictadura actúan como obstáculos, no desprendiéndose una visión satisfactoria de su propia docencia respecto al tema:

Yo hago una aproximación muy emocional a mis clases, por ejemplo, parte de mi familia vive en Francia, se exiliaron, y yo tenía un tío, yo recuerdo que vino con esa ley de amnistía [...]. Como habrás visto mi acercamiento a la Historia es emocional. Pongo mucha pasión... y es extenuante. Voy muy a tope... hasta la extenuación. No sé si son maneras. [...] dar clase de Historia no es lo mismo que hablar de piedras, de metáforas ni de matemáticas. A mí me ha afectado mucho a lo largo de todos los años porque estoy tratando de "asuntos que me comprometen". (P1, 2020. Información verbal.)

Su caso ilustra la generación de una particular intensidad y emotividad en el tratamiento educativo del franquismo, un ambiente que, como se ha señalado para el tema del Holocausto en las aulas francesas, en ocasiones podría llegar a ser un obstáculo para el aprendizaje crítico (FALAIZE, 2009). Asimismo, la Profesora 1 ilustra la existencia de una cierta incomodidad docente con un pasado que se ha vivido -a nivel personal o familiar - a menudo con dolor e 
intensidad y del que no se tiene una formación reglada y específica (GONZÁLEZ, 2014; MARTíNEZ, 2013). Existe una dificultad evidente de historizar la experiencia personal y aprovecharla a nivel didáctico, algo que en la Profesora 1 parece actuar como un factor disuasorio más para abordar estos temas de un modo detallado y consistente en el aula. En efecto, y pese a su clara voluntad de impugnar las narrativas legitimadoras del franquismo, esta docente no parece dedicar un gran espacio y un trabajo sistemático a los aspectos más controvertidos del tema, como las diversas modalidades de la represión, incurriendo en una cierta contradicción entre lo que le gustaría y se propone hacer y lo que realmente puede y consigue realizar (DELGADO, 2015; MARTíNEZ, MUÑOZ; SÁNCHEZAGUSTí, 2019). En su caso, a la difícil digestión de la experiencia biográfica y la memoria familiar se suma una visión muy negativa del sistema educativo español, que, comparándolo con el alemán -en el que ha trabajado-, percibe como obstáculo insalvable que, dada su extensión y el tipo de prueba externa de acceso a la universidad, no permite un tratamiento de la historia reciente del país más detallado y con un rol más activo del alumnado.

De resultas de todo ello, una docente con un planteamiento enormemente crítico con la transición a la democracia y la ausencia de una sólida política de memoria democrática, acaba sin embargo por desatender en cierto modo en el aula estas específicas cuestiones relacionadas con la gestión actual del pasado franquista y el problema de la impunidad de los crímenes de la dictadura. Así, no se aprecia un tratamiento sistemático de estas temáticas, que acaban subsumiéndose en sus clases en comentarios esporádicos de cuestiones como la "querella argentina" o las torturas no juzgadas del franquismo. Esta omisión parece ser una postura dominante entre el profesorado español (DELGADO, 2014; MARTÍNEZ, 2013), cuestión preocupante teniendo en cuenta que se ha detectado la existencia de actitudes de banalización y acriticismo entre el alumnado respecto a la pervivencia de los símbolos del franquismo -como el mausoleo del Valle de los Caídos-, la no-reparación de las víctimas de la represión y otras cuestiones relacionadas con las políticas de memoria (NAVARRO-MEDINA; DE ALBA, 2015; SÁNCHEZ-AGUSTí; MARTíNEZ; MIGUEL-REVILLA; LÓPEZ-TORRES, 2019). 
De este modo, la escasa presencia de las políticas de -y las luchas porla memoria incluso entre docentes que, como la Profesora 1, lo valoran a nivel social o político como algo necesario, corrobora las tensiones que genera incluir un tema sobre el que existe una fuerte discrepancia pública entre las diferentes fuerzas parlamentarias (BERNECKER; BRINKMANN, 2009) y que resulta ser marginal en los libros de texto (DÍEZ, 2020; FUERTES; IBÁÑEZ, 2019). Resulta importante resaltar, en cualquier caso, que no puede establecerse una relación causal determinista entre dichos factores y las prácticas docentes, tal y como muestran los casos de los profesores 2 y 3. Así, por ejemplo, el Profesor 2 incluye entre sus materiales la legislación memorialista que experimentó un proceso irregular de implantación en España desde 2007. En cuanto al Profesor 3, colabora con el movimiento asociativo de "recuperación de la memoria histórica", organizando charlas con familiares de víctimas del franquismo enterradas en fosas comunes durante la guerra y la posguerra o con víctimas de la represión tardofranquista, una actividad que se está extendiendo en los últimos años en numerosos institutos (FUERTES; ASENSI; FUSTER; CLAUDINO, 2021). Ejemplos ambos, en fin, que ponen en valor el carácter creativo e inventivo de la praxis docente y los márgenes de acción para abordar críticamente un tema, como el de las políticas de memoria, delicado y que genera particulares tensiones.

\section{Entre la neutralidad deseada y la elusión}

Los profesores 4 y 5 , de quienes nos ocuparemos en este último punto, comparten con la Profesora 1 la desatención a las políticas de memoria, pero, al tiempo, presentan toda una serie de características que les alejan bastante de los casos anteriores. Ambos coinciden en ser quienes con mayor superficialidad abordan el tema en 40 de ESO, mediante un tratamiento apresurado en una o unas pocas sesiones ubicadas al final del curso, limitándose a remarcar las grandes etapas de la dictadura a nivel institucional y económico y sin llegar en ningún caso al análisis del final del franquismo y el proceso de democratización. Retomando las categorías de Kelly (1986) y López Facal y Santidrián (2011) y recordando que se tratan de modelos ideales construidos con fines analíticos, estos 2 docentes podrían ubicarse a medio camino entre la "imparcialidad 
neutral" y la "neutralidad excluyente". Ambos eluden la controversia en el aula, mantienen una intención clara de no influir políticamente en el alumnado y, a menudo, tienden a una cierta equiparación entre interpretaciones historiográficas y posiciones políticas muy alejadas entre sí. El intento de alcanzar la neutralidad y de desposeer de la ideología que subyace en todo proceso de construcción de conocimiento histórico se realiza en cualquier caso de 2 modos distintos, presentando ambos docentes importantes diferencias.

El Profesor 4, que articula sus clases siguiendo el libro de texto, pone el foco en las pugnas internas entre los apoyos políticos de la dictadura y en la evolución de las políticas económicas a partir de la llegada al poder de los llamados "tecnócratas", en 1959. Aunque destaca la importancia de transmitir al alumnado la "durísima" represión de posguerra y su continuidad más allá de esta, no concede gran importancia a la represión sobre las mujeres u otras dimensiones clave trabajadas por los profesores 2 y 3 y, de facto, parece considerarla en sus clases una dimensión secundaria respecto a la evolución político-económica. Este docente, que considera la Guerra Civil y el franquismo "el tema polémico por excelencia", parece escudarse en el extenso currículo de 40 de ESO - sin cuestionar la escasa atención a la historia reciente de Españapara justificar su tratamiento superficial: "no te da tiempo a nada [...] es una asignatura [...] de locos [...] Les explico cuatro cositas de Falange y de los tecnócratas y poca cosa más" (P4, 2020. Información verbal.). Asimismo, apela implícitamente al hecho de que dicho contenido podrá abordarse en 2o de Bachillerato, tal y como se ha constatado en otras investigaciones (MARTíNEZ, 2013), olvidando que una parte considerable del alumnado no cursa dichas enseñanzas post-obligatorias y sin que argumente llevar a cabo en este último curso un tratamiento especialmente pormenorizado del tema.

Este docente, que afirma educar en el respeto a la democracia y a los Derechos Humanos, presenta una actitud pretendidamente objetiva y evitativa (TOLEDO, 2015), asumiendo que la neutralidad total buscada es inalcanzable; de este modo, articula un discurso "aséptico" desde la apelación a su rol de historiador profesional - de hecho, Doctor en Historia Contemporánea, aunque especializado en períodos anteriores al franquismo-: 
El profesor tiene que tener el afán por defender la democracia y defender los posicionamientos democráticos y paneuropeos, internacionalistas, pero al mismo tiempo pues... no degradando, ni denigrando las corrientes ideológicas, o ridiculizando las corrientes ideológicas que quizás no comparta, ¿no? Yo... hay profesores que cuando imparten el franquismo a lo mejor... algunos alumnos puede ser que hayan tenido problemas con el tema de ridiculizar, poner alguna mofa de Franco. Bueno, está bien, pero quizás yo me lo ahorraría y lo haría desde un punto de vista más científico, la crítica al franquismo, ¿no? Creo que debe ser dentro de la... no sé si elegancia, pero sí corrección política, debes ser crítico con el franquismo, con una dictadura, pero siempre intentando ser lo más aséptico posible en ese sentido. (P4, 2020. Información verbal.)

En la práctica, este profesor interioriza una narrativa algo ambivalente o insuficientemente crítica hacia el franquismo. Así, se limita a señalar globalmente su carácter dictatorial, pero sin incidir demasiado en algunas de sus políticas específicas más controvertidas y de mayor impacto negativo para el conjunto de la sociedad, en línea con un problema detectado en buena parte de los manuales escolares actuales (FUERTES, 2018a). A diferencia de los 3 docentes ya analizados, no subraya la necesidad de impugnar las narrativas escolares, políticas y mediáticas que contribuyen a normalizar la falta de una sólida política de memoria democrática y dar una imagen benévola o menos negativa de la dictadura. De hecho, no identifica determinados ejemplos de estas narrativas presentados durante la entrevista e, incluso, parece asumir parcialmente algunos aspectos de las mismas. Así, por ejemplo, aunque afirma que en sus clases trata "siempre como un ataque a la democracia" el golpe de Estado de 1936, parece compartir en cierta medida la imagen negativa de una Segunda República marcada por la "inestabilidad” (P4, 2020. Información verbal.) y la idea de una responsabilidad compartida entre las izquierdas y las derechas en el origen de la Guerra Civil.

Cuesta por ejemplo ver lo que pasa en el 34 en la República, las tendencias que algunos políticos republicanos tienen, no sé si hacia el partido único, pero sí hacia unas tendencias más autoritarias dentro de la República que existieron y son muy evidentes [...] La Segunda república no es que fuera un desastre tan grande como dijo Fraga ${ }^{3}$, "España no era un país para vivir".

\footnotetext{
${ }^{3}$ Ministro durante la dictadura y fundador de Alianza Popular, renombrada como Partido Popular y principal fuerza de la derecha española desde los años 1980
} 
Quizá era una exageración, pero sí que es cierto que es un régimen que, por tensiones de la derecha, de las clases privilegiadas que se sentían atacadas, y seguramente por algunas acciones de grupos... el 34 y tal, es un régimen que nace con una inestabilidad en algunos momentos ${ }^{4}$. (P4, 2020. Información verbal.)

Dicha narrativa o "teoría de la equidistancia" (ERICE, 2009), impulsada por la propia dictadura durante su última etapa y apuntalada durante la transición, sigue perviviendo de forma sutil en los manuales escolares (DÍEZ, 2020; FUERTES, 2018b). Tiene el efecto de diluir la responsabilidad de los golpistas en el inicio de una guerra "fratricida" - presentada como "inevitable" en relación con lo que se consideraría una excesiva politización- y, consecuentemente, en la propia configuración de la dictadura, con el correlato de que la reconciliación democrática requiere del olvido y la impunidad. Su interiorización parece llevar al Profesor 4 a leer en términos equiparadores las violencias políticas republicana/izquierdista y franquista/derechista, algo profundamente cuestionado por la historiografía académica (GIL, 2012; RICHARDS, 1999), Y que, en su caso, podría apuntalarse por una particular apropiación de la experiencia familiar: "mi abuela materna, que aún vive [...] esta es de la España vencedora [y] mis otros abuelos son de la España perdedora: tengo ahí las dos partes" (P4, 2020. Información verbal.).

Igualmente, asume una postura oficialista y complaciente hacia la transición y sus medidas de impunidad, limitando el tratamiento de las actuales políticas de memoria a comentarios aislados sobre cuestiones como "el tema de los cambios del callejero" (P4) en su ciudad, tras la eliminación por parte del ayuntamiento de nombres de cargos de la dictadura que, parece, tienen como fin más la conexión con el entorno local del alumnado que una reflexión verdaderamente problematizadora. En un nuevo ejemplo de pretensión de neutralidad y equiparación entre interpretaciones, este docente concluye:

\footnotetext{
${ }^{4}$ En 1934, durante la Segunda República, se produjo una insurrección obrera en Asturias como parte de una huelga general revolucionaria; esta contó con el apoyo de parte del socialismo español y del anarquismo, así como con una movilización paralela del republicanismo catalanista de izquierdas. Fue reprimida por el gobierno conservador con dureza, empleando el Ejército -con el propio Franco a la cabeza- para ello, y se ha interpretado como una poco consistente y limitada reacción defensiva a la llegada al poder de la crecientemente fascistizada CEDA (Confederación Española de Derechas Autónomas) en un contexto marcado por la expansión nazi en Europa y su influencia sobre Austria, así como por la reciente aparición en 1933 de un partido abiertamente fascista en España: Falange (ERICE, 2010; GIL, 2019; GONZÁLEZ CALLEJA, 2011; PRESTON, 2011).
} 
Hay mucha historiografía sobre el franquismo, de muy diverso color político, desde luego, y que la gente lea sobre el franquismo y que lea sobre la transición española y sobre el origen de nuestros partidos políticos y las mutaciones que han tenido, aunque ya existieran antes del franquismo y, a partir de ahí, que cada uno saque sus conclusiones. (P4, 2020. Información verbal.)

Por último, tal y como hemos avanzado, la Profesora 5 coincide en diversos aspectos con el posicionamiento del anterior docente, si bien se agudizan algunos de los problemas apreciados en el Profesor 4. Así, a pesar de asumir declarativamente una finalidad educativa crítica y de corregir activamente las manifestaciones abiertamente franquistas o fascistas entre el alumnado, no prioriza en sus clases el tratamiento de la historia reciente ni de los aspectos más conflictivos de la misma. Baste, como muestra que, aunque a diferencia del Profesor 4 elabora una unidad didáctica propia sobre la Guerra Civil y el franquismo e intenta aplicar diversas estrategias metodológicamente innovadoras aprendidas en el Máster de Secundaria, su enfoque del contenido resulta bastante tradicional y cercano al de los manuales escolares. El trabajo de grandes personalidades del periodo, las campañas bélicas y la división entre un primer franquismo de posguerra y un segundo franquismo desarrollista -uno de los grandes ejes de la propaganda de la dictadura- son los temas centrales de su propuesta.

La represión no aparece como elemento central de su programación, sino como actividad complementaria: una visita a unas importantes fosas comunes de fusilados por el franquismo ubicadas cerca del centro escolar -en la localidad de Paterna- en las cuales se están llevando trabajos arqueológicos de exhumación. Esta actividad, que aún no ha sido realizada, alberga en sí misma una importante potencialidad crítica (PÉREZ GUIRAO, 2018) y su elección es significativa para la comprensión de la complejidad de las representaciones y prácticas de esta docente. Sin embargo, su descontextualización respecto a la programación general del tema y algunos comentarios docentes podrían significar restar potencial formativo a la misma. Así, se refiere a la actividad subrayando su potencial procedimental y con reservas respecto a un tratamiento detallado de los hechos: 
[...] que ellos vieran también el tema de la arqueología [...] hay que comentar todas aquellas víctimas, que cada una tiene una historia, cada cual más rocambolesca, pero igual sin ser tan explícito. O yo me quedaría un poco al margen de este tipo de contenido. (P5, 2020. Información verbal.)

Algo que podría verse reforzado por su lectura del contexto social del centro católico en que trabaja, teniendo en cuenta la cercanía en España entre Iglesia y franquismo y la oposición de esta institución a las políticas de memoria democrática: "es un centro privado y... pues, tienen algunas ideas de casa" (P5, 2020. Información verbal.). Otros elementos de su relato y propuestas didácticas parecen reforzar esta hipótesis de un aprovechamiento insuficiente de esta salida escolar.

Esta docente no muestra una gran capacidad para impugnar las narrativas legitimadoras de la dictadura y la desmemoria. Dejando claro que la mayor o menor proximidad vital con los hechos no es un factor determinante, la más joven de los entrevistados muestra de una forma mucho más explícita que el Profesor 4 la interiorización de la memoria traumática y la narrativa equidistante sobre la Guerra Civil. Ello se aprecia con claridad en sus comentarios tras la proyección de un fragmento de la serie Cuéntame cómo pasó (CUETO, 2009), que trasluce una narrativa equidistante sobre el pasado reciente, incluido en la entrevista con el objetivo de valorar si los docentes son capaces de impugnar dicha lectura. Concretamente, se trata de una escena ambientada en 1969 y protagonizada por 2 excombatientes - uno republicano y uno franquista- que se dan la mano durante una misa y apuestan por mirar al futuro desde el olvido, afirmando ambos "lo pasado, pasado":

Me ha gustado mucho el fragmento [...] hay cosas que me he apuntado [...] porque me han parecido relevantes a comentar con ellos [...] El gesto bonito de las paces [...] entre ellos dos, ambos han sido víctimas de algún modo por bandos contrarios, pero ambos comparten mismos espacios y mismo tiempo, podrían ser perfectamente hermanos o familiares y, sin embargo, se han visto en puntos diferentes y enfrentados... Haríamos una reflexión sobre esto de... pues, más moral, de a qué nos lleva todo esto, el enfrentamiento directo entre... lo que conllevó una guerra civil [...] [Los alumnos] son conscientes de que ha habido disputas entre familias por un tema que, pues eso, fue política [...] El enfrentamiento civil entre una misma nación y entre hermanos. 
Creo que esos son los puntos más fuertes que tiene la Guerra Civil y que, al final, quieres concienciar de que esto no debería volverse a producir. (P5, 2020. Información verbal.)

Su interpretación de esta ficción histórica audiovisual, a menudo empleada en las aulas para tratar el franquismo, coincide con otros estudios que apuntan a los problemas de un sector del profesorado de Historia para impugnar las narrativas históricas hegemónicas en la esfera pública, aun cuando estas hayan sido profundamente cuestionadas por la historiografía académica (SÁlZ; PARRA, 2017). Así, su relato al hilo de esta escena parece reducir la Guerra Civil a un conflicto meramente político o partidista, obviando sus múltiples aristas (CASANOVA, 1994) e intuyéndose al tiempo una cierta asunción de la narrativa antipolítica franquista, que asociaría el "fracaso" de la democracia republicana a un exceso de politización: "un tema que, pues eso, fue política” (P5). En la misma línea, ubicar el mayor potencial formativo de su tratamiento en el aula en la no repetición implica una visión aproblemática del pasado y un escaso aprovechamiento del tema para una educación crítica más ambiciosa y capaz de impugnar las narrativas del franquismo y la extrema derecha. Este tipo de visiones parecen trasladarse a su práctica docente, primando una cierta inhibición y una visión equiparadora a partir de un contraste de "diferentes puntos de vista" en torno a la conflictiva historia reciente de España:

Yo intento siempre ser lo más neutral posible, o sea, porque es cátedra, o sea, soy docente y no puedo influenciar en mis alumnos la opinión que pueda tener yo en algunos aspectos, en algunos temas, por eso me gusta darles muchos puntos de vista en ese sentido, que ellos construyan a partir de causas y consecuencias de lo que hay, y que ellos valoren si eso es lo que quieren [...] Yo incluso les pongo el himno franquista [...] el republicano y les pongo todos [...] Que escuchen, lo que quiero es que vean el simbolismo que tiene y que estaban representando a un colectivo. "Este colectivo quería representar esto con estas canciones". Luego vemos que hay otros, muy parecidos, con alusión a lo mismo, o sea, al mismo sentimiento de "vamos a cambiar las cosas" [...] Y el otro punto que sería la Guerra Civil, pero es verdad que como lo trabajo a modo de proyecto, trabajan diferentes documentos, diferentes puntos de vista, al final ellos tienen bastante opinión... yo no llego a indagar qué es lo que ellos piensan, sí que ellos tienen como mucha información sobre esto, entonces ven un punto de vista, ven otro punto de vista y ellos... se montan en su cabecita lo que consideren, pero es verdad que yo ahí no entro a ver si realmente... (P5, 2020. Información verbal.) 
En este sentido, la Profesora 5 ejemplifica una estrategia claramente evitativa, con una pretensión muy clara de mantener la neutralidad y "delegar" en el alumnado, obviando que no tiene la preparación adecuada para discernir y comprender la génesis de narrativas complejas que se han trasladado hasta la actualidad (GONZÁLEZ, 2014). Este posicionamiento limita enormemente la potencialidad formativa de los temas históricos conflictivos para la construcción de una ciudadanía crítica (LÓPEZ FACAL; SANTIDRIÁN, 2011); en este caso, de forma específica, parece asociarse a una dimensión clave que diferencia a esta profesora, graduada en Geografía, de los otros cuatro: la ausencia de una formación disciplinar en Historia. Efectivamente, y en coherencia con lo apreciado por otras investigaciones (PARRA; MOROTE, 2020; YILMAZ, 2010), entendemos que ello condiciona una visión menos compleja de la Historia que, a diferencia de los otros entrevistados, tiende a igualar a la noción de "pasado" y no a la de "la interpretación del pasado" como un relato en construcción mediante un método científico-, rayando, de este modo, con el paradigma positivista al desprender el carácter conflictivo del conocimiento histórico bajo la intención de mostrar diversos puntos de vista.

\section{Conclusiones}

A lo largo de estas páginas hemos tratado de analizar 5 casos de docentes desde el punto de vista de su acercamiento a la dictadura franquista como tema histórico escolar. El esfuerzo analítico realizado se ha concretado en un trabajo de diferenciación y clasificación de los 5 casos estudiados que, conviene resaltarlo, no pretende entender sus prácticas docentes como rígidas y monolíticas, sino detectar tendencias que puedan dar lugar a contradicciones y a diversos modos de actuar según los contextos. En conjunto, se aprecia que las representaciones y prácticas docentes analizadas se caracterizan por la complejidad y el dinamismo, en relación con variables como las diferencias entre cursos, el perfil de los centros educativos o la evolución del contexto sociopolítico.

Esta primera aproximación al tema nos ha permitido detectar la existencia de posibilidades y márgenes de acción de los docentes para un abordaje crítico 
y en profundidad de la dictadura franquista, lo cual debe hacernos huir de visiones simplistas excesivamente pesimistas o juiciosas respecto al profesorado de educación secundaria. Al tiempo, sin embargo, a través del análisis de lo que dicen hacer cuando abordan este pasado traumático y de los materiales didácticos que utilizan, hemos detectado cómo algunos docentes tienen verdaderas dificultades para llevar a cabo una enseñanza del franquismo coherente con la intención declarada de educar en los Derechos Humanos y construir una ciudadanía capaz de impugnar las narrativas franquistas o acríticas desde el conocimiento histórico riguroso. En este sentido, el énfasis de nuestro trabajo en estas dificultades se puede explicar por la incidencia de factores que hemos ido rastreando como la falta de formación disciplinar y didáctica, el escaso impulso curricular al tratamiento de la historia reciente, la falta de una memoria democrática transversal en la sociedad española o las trayectorias biográficas/familiares de los propios docentes.

En cualquier caso, dicho énfasis en las dificultades respecto a las posibilidades no tiene ninguna pretensión de generalización o representatividad, respondiendo exclusivamente al análisis en profundidad de los primeros 5 casos docentes estudiados en una investigación de mucho mayor recorrido. En este sentido, este trabajo presenta innegables limitaciones, pero pretende ser un primer paso para seguir profundizando en el futuro en una serie de dimensiones detectadas que requieren de un estudio más detallado para una comprensión más amplia y compleja de la enseñanza de la dictadura de Franco en la España actual.

\section{Referencias}

ACEITUNO, David. La enseñanza de la transición dictadura-democracia en Chile: un estudio sobre el profesorado de historia de 2. medio. 2012. Tesis (Doctorado en Didáctica de las Ciencias Sociales) - Universidad de Valladolid, Valladolid, 2012.

AGUILAR, Paloma. La evocación de la guerra y del franquismo en la política, la cultura y la sociedad españolas. In: JULIÁ, Santos (dir.). Memoria de la guerra y del franquismo. Madrid: Taurus, 2006. p. 279-317. 
ALONSO, Luis Enrique. Sujeto y discurso: el lugar de la entrevista abierta en las prácticas de la sociología cualitativa. In: DELGADO, José Manuel; GUTIÉRREZ, Juan (coords.). Métodos y técnicas cualitativas de investigación en ciencias sociales. Madrid: Síntesis, 1995. 224-240.

BABIANO, José; GÓMEZ, Gutmaro; MíGUEZ, Antonio; TÉBAR, Javier. Verdugos impunes: el franquismo y la violación sistémica de los derechos humanos. Barcelona: Pasado \& Presente, 2017.

BALDÓ, Marc. De les memòries dividides a la memòria democrática. In: ANDREU, Frechina i; VICENT, Josep (coord.). La memòria històrica i democràtica: experiències i propostes en el territorio valencià: trobada Universitat de València-Institut d’Estudis Comarcals. València: Universitat de València, 2017. p. 15-24.

BELTRÁN, José; MARTíNEZ, Nicolás; SOUTO, Xosé Manuel. Los profesores de Historia y la enseñanza de la historia de España. Enseñanza de las ciencias sociales: revista de investigación, Barcelona, n. 5, p. 55-71, 2006.

BERNECKER, Walter L; BRINKMANN, Sören. Memorias divididas: guerra civil y franquismo en la sociedad y la política españolas: 1936-2008. Madrid: Abada: Sociedad Estatal de Conmemoraciones Culturales, D. L., 2009.

BISQUERRA, Rafael. Metodología de investigación educativa. Madrid: La Muralla, 2014.

CARRETERO, Mario; BORRELLI, Marcelo. Memorias recientes y pasados en conflicto: ¿cómo enseñar historia reciente en la escuela? Cultura y Educación, Salamanca, v. 20, n. 2, p. 201-215, 2008.

CASALS, Xavier. De Fuerza Nueva a Vox: de la vieja a la nueva ultraderecha española (1975-2019). Ayer, Madrid, n. 118, p. 365-380, 2020.

CASANOVA, Julián. Una dictadura de cuarenta años. In: CASANOVA, Julián (coord.). Morir, matar, sobrevivir: la violencia en la dictadura de Franco. Barcelona: Biblioteca de Bolsillo, 2002. p. 2-50.

CASANOVA, Julián. Guerra Civil, ¿lucha de clases?: el difícil ejercicio de reconstruir el pasado. Historia social, València, n. 20, p. 135-150, 1994.

CHERVEL, André. Historia de las disciplinas escolares: reflexiones sobre un campo de investigación. Revista de Educación, Madrid, n. 295, p. 59-111, 1991.

CLARK, Christopher; YINGER, Robert. Teachers' thinking. In: PETERSON, Penelope L.; WALBERG, Hebert J. (coords.). Research on teaching: concepts, findings and implications. [S.l.]: McCutchan Publishing Corporation, 1979. 
CUÉNTAME cómo pasó, capítulo 46. Miguel Ángel Bernardeau. In: GRUPO GANGA. [S.L.]: TVE, 2001.

CUESTA, Raimundo. Historia con memoria y didáctica crítica. Con-ciencia social: anuario de didáctica de la geografía, la historia y las ciencias sociales,

Salamanca, n. 15, p. 15-30, 2011.

CUETO, Elena. Memorias de progreso y violencia: la Guerra Civil en Cuéntame cómo pasó. In: LÓPEZ, Francisca; CUETA, Elena; GEORGE, David R. (coords.).

Historias de la pequeña pantalla: representaciones históricas en la televisión de la España democrática. Madrid: Vervuert Iberoamericana, 2009. p. 137-157.

DE GREIFF, Pablo. Informe del relator especial sobre la promoción de la verdad, la justicia, la reparación y las garantías de no repetición, Pablo de Greiff. [S.l.]: Organización de las Naciones Unidas, 2014. Disponible en:

https://digitallibrary.un.org/record/780611. Acceso en: 27 feb. 2021.

DELGADO-ALGARRA, Emilio José. Educación para la ciudadanía en la enseñanza de las ciencias sociales y su vinculación con las dimensiones de la memoria: estudio de caso en ESO. 2014. Tesis (Doctorado en Didáctica de las Ciencias Sociales) - Universidad de Huelva, Huelva, 2014.

DÍEZ, Enrique Javier. La asignatura pendiente. la memoria histórica democrática en los libros de texto escolares. Madrid: Plaza y Valdés, 2020.

ERICE, Francisco. Guerras de la memoria y fantasmas del pasado: usos y abusos de la memoria colectiva. Oviedo: Eikasia, 2009.

ERICE, Francisco. El octubre asturiano. Entre el mito y la interpretación histórica. In: MARTÍN, José Luis; ANDREASSI,Alejandro (coords.). De un octubre a otro: revolución y fascismo en el período de entreguerras, 1917-1934. Barcelona: El Viejo topo, 2010. p. 199-250.

ESPAÑA. Ley 46/1977, de 15 de octubre, de Amnistía. Boletín Oficial del Estado, Madrid, 17 oct. 1977. Disponible en: https://www.boe.es/buscar/act.php?id=BOEA-1977-24937. Acceso en: 28 feb. 2021.

EVANS, Ronald W. Teachers conceptions of history revisited: ideology, curriculum, and student belief. Theory and Research in Socials Education, Florida, n. 32, v. 2, p. 101-138, 1990.

EVANS, Ronald W; NEWMANN, Fred M; SAXE, David Warren. Defining issuescentered education. In: EVANS, Ronald; SAXE, David Warren (coords.). Handbook of teaching social issues. Washington: National Council for the Social Studies, 1996. p. 2-5. 
FALAIZE, Benoit. L'ensenyament de la Shoah davant d'altres temes controvertits a l'escola francesa: reptes pedagògics i de memòria. In: PAGÈS, Joan; GONZÁLEZ, María Paula (coords.), Història, memòria i ensenyament de la història: perspectives europees i llatinoamericanes. Barcelona: Universitat Autònoma de Barcelona, Servei de Publicacions, 2009. p. 69-80.

FALAIZE, Benoit. El método para el análisis de los temas sensibles de la historia. In: ÁVILA, Rosa María; GRACIA, María Pilar; DOMínGUEZ, Pedro L. (coords.). Metodología de investigación en didáctica de las ciencias sociales. España: Institución Fernando el Católico, 2010. p. 187-2010.

FLICK, Uwe. Introducción a la investigación cualitativa. Madrid: Morata, 2007.

FUERTES, Carlos. La dictadura franquista en los manuales escolares recientes: una revisión crítica. Revista Historia Autónoma, Madrid, n. 12, p. 279-297, 2018a.

FUERTES, Carlos. La Guerra Civil española en los libros de texto de la democracia: apogeo y pervivencia de la narrativa equidistante. In: VALERO, Sergio; GARCÍA CARRIÓN, Marta. Desde la capital de la República: nuevas perspectivas y estudios sobre la Guerra Civil española. València: PUV, 2018b. p. 359-378.

FUERTES, Carlos. Pervivencias en las narrativas sobre la dictadura franquista en Los manuales escolares recientes. In: PARRA MONSERRAT, David; FUERTES MUÑOZ, Carlos (coords.). Reinterpretar la tradición, transformar las prácticas: ciencias sociales para una educación crítica. València: Tirant lo Blanch, 2019. p. 209-219.

FUERTES, Carlos. Viviendo en dictadura: la evolución de las actitudes sociales hacia el franquismo. Granada: Comares, 2017.

FUERTES, Carlos; IBÁÑEZ, Mélanie. La represión franquista en los manuales escolares: el problemático tratamiento de un tema histórico conflictivo.

Didáctica de las ciencias experimentales y sociales, València, n. 37, p, 3-18, 2019.

FUERTES, Carlos, ASENSI, Elvira, FUSTER, Carlos y CLAUDINO, Sergio. Socially acute questions and critical citizenship in trainee geography and history teachers: from theory to classroom observation. In: GÓMEZ-CARRASCO, Cosme; MIRALLES-MARTÍNEZ, Pedro; LÓPEZ-FACAL, Ramón (eds.). Handbook of research on teacher education in history and geography. Berlin: Peter Lang, 2021. p. 241-258.

GIL, Pablo. Violencia en la guerra civil y equidistancia: argumentos para no sucumbir al embrujo irresistible del punto medio. Hispania Nova. Revista de Historia Contemporánea, Madrid, n. 10, 2012.

GIL, Pablo. Verdugos de Asturias: la violencia y sus relatos en la revolución de Asturias de 1934. Gijón: Trea, 2019. 
GONZÁLEZ, José Ramón. Los pasados recientes en conflicto y sus implicaciones didácticas: Guerra civil y transición. Con-ciencia social: Anuario de didáctica de la geografía, la historia y las ciencias sociales, Salamanca, n. 18, p. 157-164, 2014.

GONZÁLEZ, María Paula. La enseñanza de la historia en el siglo XXI: saberes y prácticas. Los Polvorines: Universidad Nacional de General Sarmiento, 2018.

GONZÁLEZ, María Paula. La historia reciente en la escuela: saberes y prácticas docentes en torno a la última dictadura. Los Polvorines: Universidad Nacional de General Sarmiento, 2014.

GONZÁLEZ CALLEJA, Eduardo. Contrarrevolucionarios: radicalización violenta de las derechas durante la Segunda República, 1931-1936. Madrid: Alianza, 2011.

GOODSON, Ivor (coord.) Historias de vida del profesorado. Barcelona: Octaedro, 2004.

GUIMERÁ, Carmen. Práctica docente y pensamiento del profesor de historia secundaria. 1992. Tesis (Doctorado en Didáctica de las Ciencias Sociales) Universitat de Barcelona, Barcelona, 1992.

HERNÁNDEZ, Fernando. La enseñanza de la historia del presente en la España actual: entre al agujero negro y el relato intencional, Studia Histórica. Historia Contemporánea, Salamanca, n. 32 p. 57-74, 2014.

HERNÁNDEZ, Fernando; SANCHO, Juana María. El papel de la formación en las historias de vida del docente, Cuadernos de pedagogía, Madrid, n. 374, p. 40-43, 2007.

IBÁÑEZ, Mélanie. ¿Alguien hablará de nosotras cuando hayamos muerto?: sobre género, franquismo y didáctica. Didácticas Específicas, Madrid, n. 14, p. 50-70, 2016.

KELLY, Thomas. E. Discussing controversial issues: four perspectives on the teachers's role. Theory and Research in Social Education, Silver Spring, n. 14, v. 2, p.113-138, 1986.

KRIGER, Miriam. La enseñanza de la historia reciente como herramienta clave de la educación política: narrativas escolares y memorias sociales del pasado dictatorial argentino en las representaciones de jóvenes estudiantes de la Ciudad de Buenos Aires y conurbano (2010-2011). Persona y Sociedad, Santiago de Chile, n. 25, v. 3, p. 29-52, 2011. 
LAMIKIZ, Amaia. El lugar de la memoria en nuestras clases de historia. In: LÓPEZ FACAL, Ramón et al. (eds.). Pensar históricamente en tiempos de globalización: actas de I Congreso Internacional sobre enseñanza de la historia. Santiago de Compostela: USC, 2011. p. 99-110.

LEGARDEZ, Alain; SIMONNEAU, Laurence. L'école à l'épreuve de l'actualité: enseigner les questions vives. Issy les Moulineaux: ESF, 2006.

LÓPEZ FACAL, R; SANTIDRIÁN, Víctor Manuel. Los "conflictos sociales candentes” en el aula. Íber. Didáctica de las Ciencias Sociales, Geografía e Historia, València, n. 69, p. 8-20, 2011.

MAESTRO, Pilar. El modelo de las historias generales y la enseñanza de la historia. Didáctica de las Ciencias Experimentales y Sociales, [s.l.], n. 16, p. 3-33, 2002.

MAINER, Juan. El pasado traumático en la historia escolar española: la presencia de una ausencia. In: MAGALHÃES, Lívia Diana Rocha; DIAS, José Alves (orgs.). Memória com história da educação: desafios eminentes. Uberlândia: Navegando Publicações, 2020, p. 3-17.

MARTÍNEZ, Rosendo. Profesores entre la historia y la memoria: un estudio sobre la enseñanza de la transición dictadura-democracia en España. 2013. Tesis (Doctorado en Didáctica de las Ciencias Sociales) - Universidad de Valladolid, Valladolid, 2013.

MARTíNEZ, Rosendo; MUÑOZ, Carlos; SÁNCHEZ-AGUSTí, María. Conocimientos y creencias del profesorado y su vínculo con las finalidades de la enseñanza de la historia reciente: la transición a la democracia en España como caso controvertido. Revista de Educación, Madrid, n. 383, p. 11-35, 2019.

MERCHÁN, Francisco Javier. Enseñanza, examen y control: profesores y alumnos en la clase de historia. Barcelona: Octaedro: EUB, 2005.

MONTEIRO, Ana María. Professores de história: entre saberes e práticas. Rio de Janeiro: Mauad, 2007.

NAVARRO-MEDINA, Elisa; DE ALBA, Nicolás N. El posicionamiento de los jóvenes en España con respecto a la guerra civil y la memoria histórica: entre la reproducción y el pensamiento crítico. In: HERNÁNDEZ CARRETERO, Ana María; GARCÍA RUIZ, Carmen Rosa; DE LA MONTAÑA CONCHIÑA, Juan Luis (eds.). Una enseñanza de las ciencias sociales para el futuro: recursos para trabajar la invisibilidad de personas, lugares y temáticas. Extremadura: Universidad de Extremadura: Asociación Universitaria de Profesores de Didáctica de las Ciencias Sociales, 2015. p. 933-941. 
MONTOTO, Marina. "Nosotros también somos víctimas": las luchas por la justicia y el reconocimiento de las víctimas del franquismo en la Querella Argentina. Revista de Antropología Social, Madrid, n. 29, v. 2, p. 199-211, 2020.

P1. [Entrevista cedida a] Néstor Banderas Navarro, València (España), 21 oct. 2020.

P2. [Entrevista cedida a] Néstor Banderas Navarro, València (España), 27 oct. 2020.

P3. [Entrevista cedida a] Néstor Banderas Navarro, València (España), 12 nov. 2020.

P4. [Entrevista cedida a] Néstor Banderas Navarro, València (España), 19 nov. 2020.

P5. [Entrevista cedida a] Néstor Banderas Navarro, València (España), 15 dic. 2020.

PARRA, David; MOROTE, Álvaro. Memoria escolar y conocimientos didácticodisciplinares en la representación de la educación geográfica e histórica del profesorado en formación. Revista Interuniversitaria de Formación del Profesorado, Murcia, n. 95, p. 11-32, 2020.

PENNA, Fernando de A. O discurso reacionário de defesa do projeto 'Escola sem Partido': analisando o caráter antipolítico e antidemocrático. Quaestio-Revista de Estudos em Educação, [s. l.], v. 20, n. 3, p. 567-581, 2018.

PÉREZ GÓMEZ, Ángel. O pensamento prático do professor: a formação do professor como profissional reflexivo. In: Nóvoa, António. (org.). Os professores e sua formação. Lisboa: Dom Quixote, 1995. p. 93-114.

PÉREZ GUIRAO, Francisco Javier. Memoria, historia y escuela: una aproximación etnográfica tras la exhumación de las 17 rosas de Guillena. Enseñanza de las Ciencias Sociales, Barcelona, n. 17, p. 61-71, 2018.

PRESTON, Paul. El holocausto español: odio y exterminio en la Guerra Civil y después. Barcelona: Debate, 2011.

PRESTON, Paul. Un poble traït: corrupció, incompetència política i divisió social. Espanya des del 1876 fins a l'actualitat. Barcelona: Base, 2019.

REDON, Silvia; ANGULO, José Félix. (coords.). Investigación cualitativa en educación. Buenos Aires: Miño y Dávila, 2017.

RICHARDS, Michael. Un tiempo de silencio: la guerra civil y la cultura de la represión en la España de Franco, 1939-1945. Barcelona: Crítica, 1999. 
RODRÍGUEZ, Olga. La guerra contra la memoria: demandas contra investigadores e impunidad para crímenes franquistas. El diario, Madrid, 2021. Disponible en: https://www.eldiario.es/sociedad/guerra-memoria-demandasinvestigadores-e-impunidad-crimenes-franquistas_1_7233036.html. Acceso en: 28 feb. 2021.

RUIZ OLABUÉNAGA, José Ignacio. Metodología de la investigación cualitativa. Bilbao: Universidad de Deusto, 2009.

RÜSEN, Jörn. Historical consciousness: narrative structure, moral function, and ontogenetic development. In: SEIXAS, Peter (coord.). Theorizing historical consciousness. Toronto: University of Toronto Press, 2004. p. 63-84.

SÁlZ, Jorge; PARRA, David. Formación del profesorado de historia y ficción televisiva: el aprovechamiento didáctico de las series históricas en educación secundaria. Revista electrónica interuniversitaria de formación del profesorado, [s.l.], v. 20, n. 2, p. 95-109, 2017.

SANTIAGO, Borja. La transición española en 4. ESO: un estudio de caso de los significados. Panta Rei. Revista Digital de Ciencia y Didáctica de la Historia, Murcia, n. 4, p. 121-134, 2014.

SÁNCHEZ-AGUSTII, María; MARTíNEZ, Rosendo; MIGUEL-REVILLA, Diego; LÓPEZTORRES, Esther. Ideas de los jóvenes españoles acerca del pasado reciente: el caso de la transición a la democracia. El Futuro del Pasado, Salamanca, n. 10, p. 215-255, 2019.

SAZ, Ismael. El «moment memòria»: justícia, veritat i reconciliació democràtica. Afers, València, n. 56, 27-40, 2007.

SAZ, Ismael. Fascismo y franquismo. València: Universitat de València, 2004.

STRAUSS, Anselm; CORBIN, Juliet. Bases de la investigación cualitativa: técnicas y procedimientos para desarrollar la teoría fundamentada. Medellín: Universidad de Antioquia, 2002.

TOLEDO, María Isabel. Enseñanza de "temas controversiales" en la asignatura de historia, desde la perspectiva de los profesores In: PAGĖS, Joan; SANTISTEBAN, Antoni (coords.). Una mirada al pasado y un proyecto de futuro: investigación e innovación en didáctica de las ciencias sociales. Barcelona: Universitat Autònoma de Barcelona, Servei de Publicacions, 2015. p. 21-28.

TRILLA, Jaume. El profesor y los valores controvertidos: neutralidad y beligerancia en la educación. Barcelona: Paidós, 1992. 
TUTIAUX-GUILLON, Nicole. Le difficile enseignement des «questions vives» en histoire-géographie. In: LEGARDEZ, Alain; SIMONNEAUX, Laurence (coords.). L'école à l'épreuve de l'actualité: enseigner les questions vives. Issy les Moulineaux: ESF éditeur, 2006. p. 119-135.

VALLS, Rafael. Historia y memoria escolar: Segunda República, Guerra Civil y dictadura franquista en las aulas. València: PUV, 2009.

WATERSON, Robert A. The examination of pedagogical approaches to teaching controversial issues: explicity teaching the holocaust and comparative genocide. Social Studies Research and Practice, Seattle, n. 4, v. 2, 2009.

YILMAZ, Kaya. Social studies teachers' conceptions of history: calling on historiography. The Journal of Educational Research, Belfast, n. 101, v. 3, p. 158176, 2010.

VIÑAS, Ángel. La otra cara del caudillo: mitos y realidades en la biografía de Franco. Barcelona: Crítica, 2015. 